\title{
Implications of Lender Values for Risk Management in the Microfinance Industry
}

\author{
Kieran Ball ${ }^{1,2}$ \& John Watt ${ }^{1}$ \\ ${ }^{1}$ Centre for Decision Analysis and Risk Management, School of Science and Technology, Middlesex University, \\ UK \\ ${ }^{2}$ Vittana Foundation \\ Correspondence: John Watt, Centre for Decision Analysis and Risk Management, School of Science and \\ Technology, Middlesex University, The Burroughs, Hendon, London NW4 4BT, UK. Tel: 44-208-411-6822. \\ E-mail: J.Watt@mdx.ac.uk
}

Received: April 23, 2013

Accepted: August 8, 2013

Online Published: August 26, 2013

doi:10.5539/ijef.v5n9p1

URL: http://dx.doi.org/10.5539/ijef.v5n9p1

\begin{abstract}
This paper investigates the extent to which the microfinance sector should be influenced by risk management policies from the banking industry. The increasing commercialisation of microfinance is resulting in a greater impetus to implement formal risk policies and practices. Such actions, if conceived with due care and attention to the purpose of microfinance, could be an important step for the industry. However, there is a danger that generic procedures of risk assessment and management, particularly those adapted from purely for-profit industries, could impede this relatively young industry, or subvert its mission.

The discussion centres around a survey of public opinion on the riskiness of a range of investment options and the factors that influence investment decisions, seeking to determine whether the public's perception of the riskiness might be affected by qualitative factors, such as societal benefits. The survey finds no relationship between overall risk perception and the qualitative factors tested, but does suggest that investment decisions can be explained by two opposing dimensions: social and financial. This leads to a number of implications for the evolution of risk management within the microfinance industry, and highlights dangers of focusing purely on technical risk.
\end{abstract}

Keywords: governance, lenders, microfinance, risk, sustainability, values

\section{Introduction}

Although microfinance has been practiced worldwide in various forms for several centuries, in the last few decades it has become a more formalised industry, caught up in a wider drive, originating from the banking sector, which aspires to better governance practices and sustainable financial performance. These aspirations have, in turn, entrained the use of a variety of qualitative and quantitative risk management tools. However, microfinance is a specialist sector with its own distinct objectives and motivations, and research has clearly identified that its success and penetration is influenced by both socio-political factors (Rahman \& Luo, 2011; Al-Azzam, Mimouni \& Ali, 2012; Al-Mamun, Adaikalam \& Wahab, 2012) as well as operational subtleties (Ayayi, 2012; Bhattamishra \& Barrett, 2010; Hartaska \& Nadolnyak, 2007).

In this paper we are particularly concerned with the influx to microfinance of new practices related to the management of risk which emanate from the formal, for-profit, banking sector and our fundamental question is:

To what extent should risk management practices from the formal banking sector determine the risk management policies of microfinance institutions?

From this three sub-questions arise:

1) How much influence should values have in formulating risk policies?

2) Do differences between the perceptions and attitudes of stakeholders of the banking industry and the microfinance industry lead to the need for different risk policies and hence approaches to risk management?

3) Should the microfinance industry incorporate its own value system into its risk policies? 
Microfinance here refers to the provision of financial services to poor people who are excluded from the formal financial sector, with the aim to aid poverty alleviation. The growth of microfinance institutions (MFIs) since the 1970s has been rapid - there are now thought to be in the region of 10,000 MFIs operating globally with investments projected to rise to $\$ 20$ billion by 2015 (ADA, 2006; Dieckmann, 2007). This has led the sector to gain much attention from the traditional finance industry, as well as social organisations, academics, and microfinance practitioners, not to mention the media.

The consequence has been that the microfinance industry receives funding from a wide range of donors and investors with a variety of different characteristics, motivations, business models, risk appetites, and pre-conceptions about the aim of microfinance (Figure 1). Over 350 foundations and 90 specialised microfinance investment vehicles are among the funders, as well as governments, charities, development agencies, development banks such as the World Bank and UN Capital Development Fund, international NGOs, institutional investors, and private individual investors including both high net-worth and ordinary 'retail' investors. In fact, the split between donors and investors is approximately fifty-fifty (CGAP, 2008).

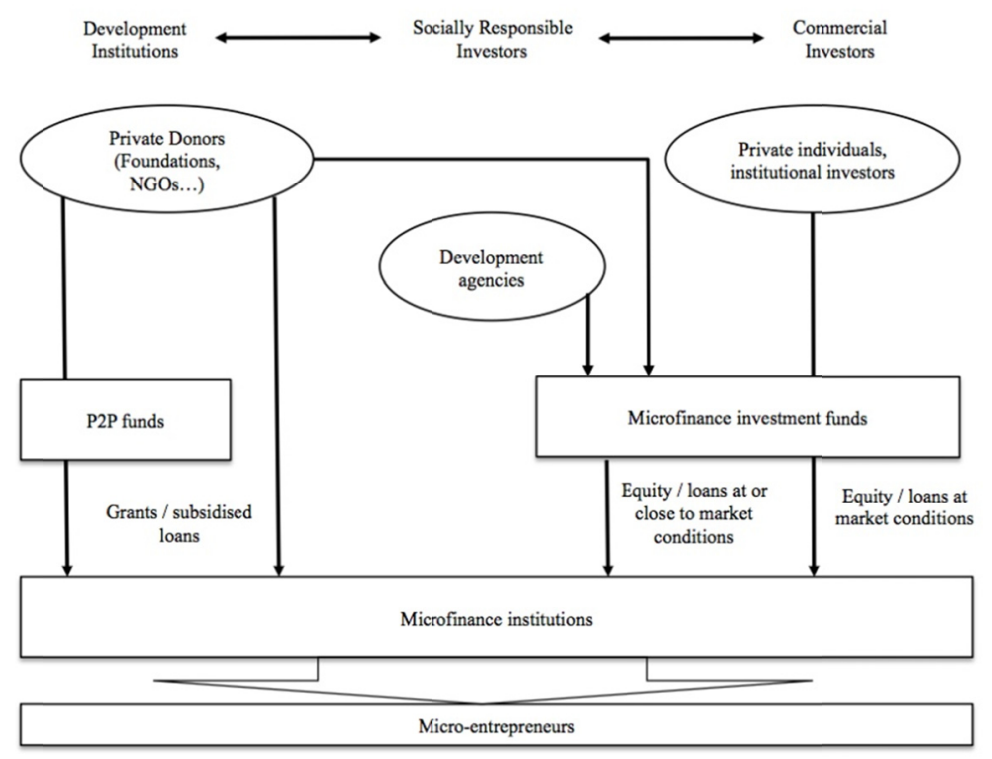

Figure 1. The different funders of the microfinance industry (adapted from Microfinance Investment Funds: Key Features; Goodman, 2005)

At the outset of the growth surge in the 1970s the motives were purely social, as pioneered initially by Yunus (1999) and since replicated by NGOs, governments, and international agencies that saw an opportunity to increase financial inclusion and reduce poverty in countries where years of aid had had little impact. It was only later, when it was discovered that microfinance was actually a viable, and even profitable, business, that investors with dual motives of profit and social impact began to take an interest. As a result, the past twenty years has seen a significant increase in the diversity of institutions providing financial services to the poor, as NGOs transformed into regulated financial entities, commercial banks entered the market, specialised microfinance banks started up, and cooperatives and rural banks increased their involvement. The consequence of this is that the main stakeholders in the microfinance industry come from two very different backgrounds. One represented by the multinational banks, pension funds and investment funds that is at least to some extent focused on profit maximisation, and a second, represented by the NGOs, donors, foundations, development agencies and the general public, for which profit, and sometimes even sustainability, may not be primary considerations or motivators.

There is no doubt that the importation of many tried-and-tested risk management techniques has been valuable for the microfinance industry, particularly with regards to basic credit risk management techniques (Fernando, 2007). Yet a comparatively rarely discussed topic is whether the social mission of the microfinance industry is compatible with the technical and process-driven risk management techniques used in the banking industry, an industry whose primary aim is profit maximisation. Banking industry regulation often stems from crises or 
scandals, meaning they are conceived and implemented rapidly, often more for compliance purposes than to add value to the business model. Adopting a similar approach, particularly at such early stages, might be incompatible with the wider and specific interests of the microfinance industry.

In order to investigate this matter we describe in Section 2 the implementation of a survey technique for eliciting underlying preferences from microfinance lenders and potential lenders. The subsequent survey data, and their statistical analysis, are reported in Section 3, using methodologies from psychometrics which have themselves been used widely in studying risk attitudes (see, for example, Slovic, 2010). Section 4 discusses the implications of the results for microfinance institutions with respect to policy issues, the management of risk, and lender preferences. Section 5 summarises the main themes to emerge from this paper which we consider MFIs need to reflect upon.

\section{Methodology}

To answer the questions posed we investigated the perceptions and motivations of a sample of the general public regarding their views of the riskiness and the functions of a range of investment options. A convenience sample of 55 respondents was used, primarily drawn from contacts and associates. Such a sampling strategy may have introduced a number of biases that limit the extrapolation of the data to the wider public. It was felt, however, that it was suitable for obtaining an initial group that would have sufficient awareness of finance, micro-finance and philanthropy to elicit preliminary indications of attitudes to risk and motivation. A wider or more random sample would be likely to capture many people that did not invest or give to charity. The prevalence of captured views from a wider population could, of course, be evaluated later.

A large proportion of the participants had a minimum of a university degree, and worked in academia, financial services, or in the development or non-profit field. Knowledge of P2P (Note 1) (peer to peer) microfinance websites was higher among this group than the general population. In addition, the data collection methodology which utilised email required that participants be computer literate. Thirty-six of the 55 respondents were male, and the spread of ages ranged from under twenty-five to over sixty-five. The UK and USA were the most common countries of origin, with 15 countries represented overall. Twenty-four of the participants had made a loan on a P2P website.

The questionnaire asked each participant to perform two tasks. The first was to rate seven investment options according to their 'riskiness.' 'Riskiness' was purposely not defined in order to capture as much of the participants personal perspective on risk as possible. The seven options were:

1) Money deposited in ordinary bank account.

2) Money lent on Kiva.org (Note 2) (loans made via a website to poor individuals in developing countries to help them start businesses and improve their standard of living).

3) Money invested in shares.

4) Money invested in ethical investments.

5) Money invested in hedge fund.

6) Donation to charity.

7) Money invested in pension (occupational or private).

The second task was to rate each investment option against nine qualitative factors in terms of their importance in the decision-making process when considering whether to invest. The factors were:

1) Return on investment.

2) Reputation of institution.

3) Credit rating of institution.

4) Risk of losing investment (Note 3).

5) Proximity to end beneficiary of investment (Note 4).

6) Feedback (information on what your money is used for).

7) Professionalism and experience of institution.

8) Social impact of investment.

9) Control (over how the investment is used).

Several of the factors, such as proximity, feedback, and control, were specifically chosen with P2P microfinance 
in mind, as this is where it is generally different to other investment types. 'Charity' was chosen to assess how closely aligned microfinance investments are with charitable giving over financial investments, even though some of the factors are not applicable to it, such as risk of losing investment (as the investment is a donation).

\section{Results and Data Analysis}

The questionnaire data were first analysed to determine if there was a difference in the importance of the qualitative decision factors across the investment options, and secondly to see if there were correlations between these factors and the overall perceptions of riskiness.

Figure 2 shows the average scores for the overall perception of riskiness, as well the scoring for each of the nine qualitative factors per investment option. As might reasonably have been expected, Figure 2 confirms that bank accounts were most consistently rated as low risk, while hedge funds were most consistently rated as high risk. It can also be seen that some qualitative factors, such as reputation and professionalism, are, on average, rated as important factors for all investment types, while other factors, such as risk, proximity, and social impact, exhibit noticeable differences in importance across the investment options.

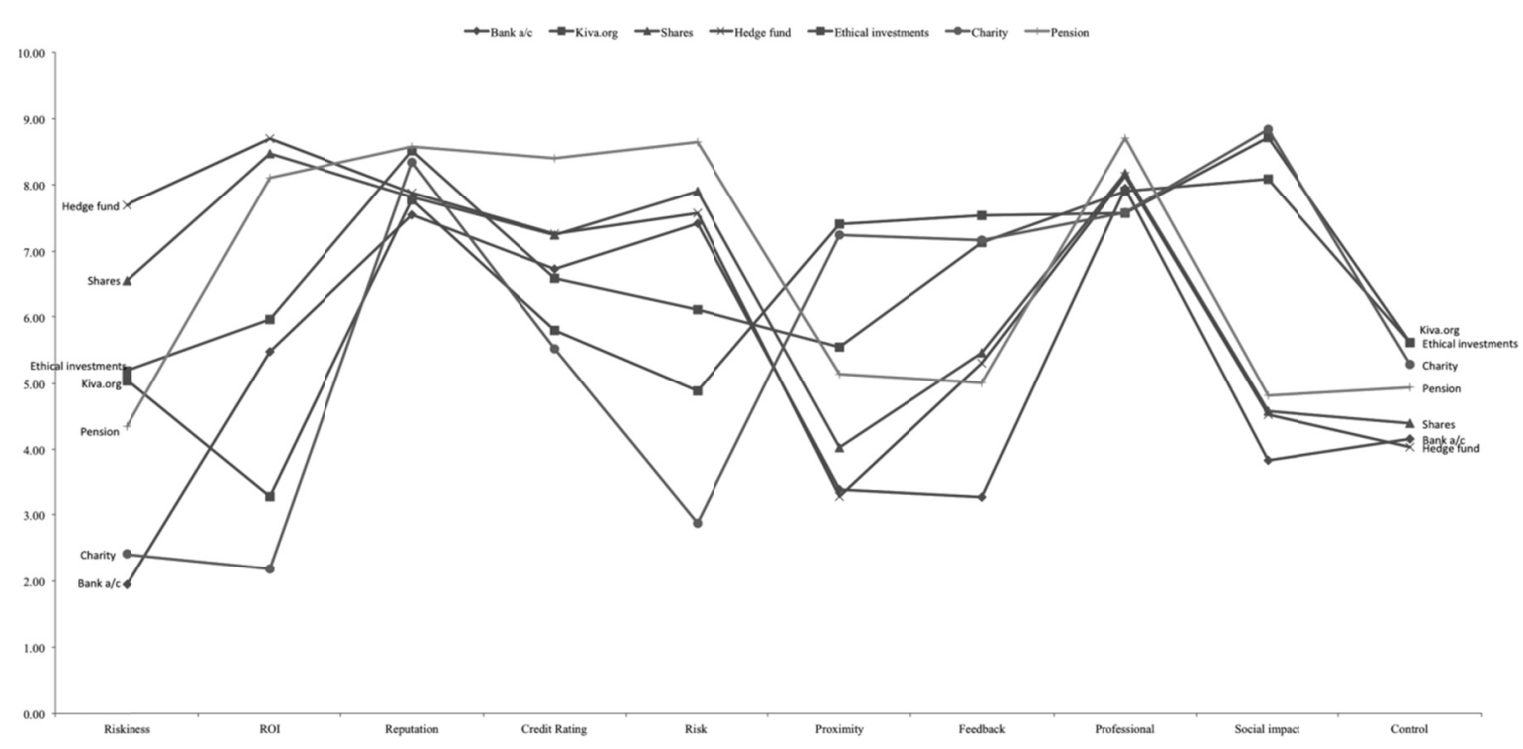

Figure 2. Graph of mean scores of riskiness and qualitative factors against investment type

The broadest spread of results is from the overall risk perceptions of each of the investment options, ranging from just under 2 to over 7.5 (out of 10). Broad spreads can also be observed on the factors return on investment and risk. For pensions, hedge funds and shares, return on investment is of high importance, while for Kiva.org and charity, return on investment is of lower importance. It is also noticeable that factors which are important when choosing to invest in Kiva.org follow a similar 'fingerprint' to those that are important when donating to charity, a pattern different from that exhibited by shares or bank accounts.

Figure 3 shows in more detail the spread of responses regarding the overall perceived risk of each investment type, and Figure 4 the spread of responses for two important qualitative variables, namely, risk of losing one's investment and the social impact of the investment. What is evident is that risk is considered to be an important factor when choosing to invest in bank accounts, hedge funds, pensions and shares, but is less important for ethical investments and Kiva.org. On the other hand, the importance of social impact also varies, showing that this is of moderate importance with hedge funds, pensions, and shares, and that it is of high importance for Kiva.org, ethical investments and charitable donations. 


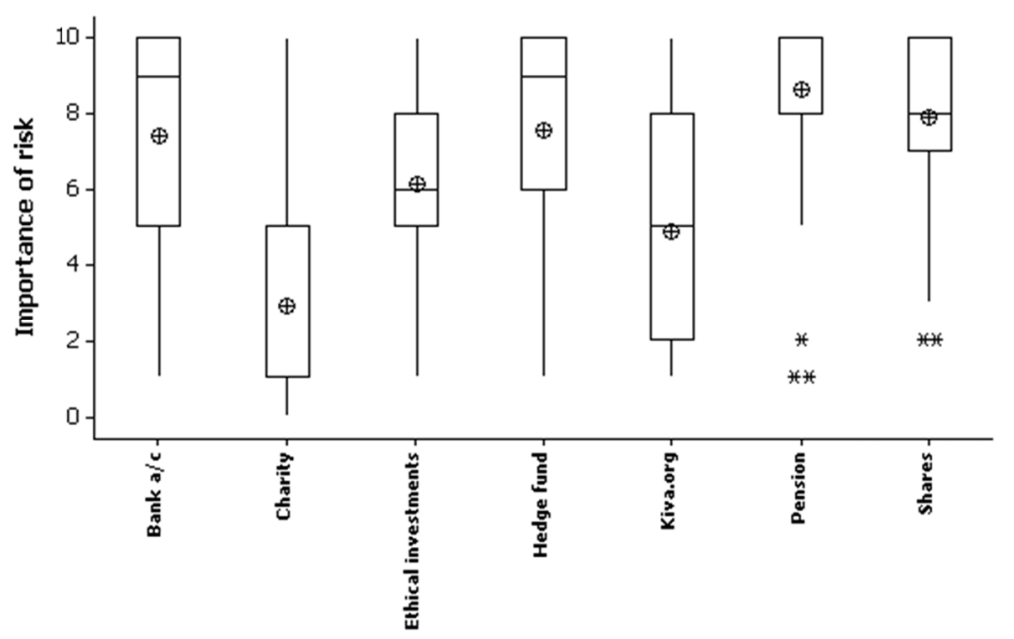

Figure 3. The perceived risk of different investment options

Note: Y-axis scale: $0=$ low overall risk; $10=$ high overall risk.

The extent of the correlation between the risk perception of an investment option and any of the qualitative factors chosen, or between the qualitative factors themselves was evaluated. One might postulate that, for example, there would be a positive correlation between the risk level and the importance of return on investment, as the risk-return relationship is one of the key principles of financial theory. To this effect Table 1 shows firstly the inter-correlations between the qualitative factors, calculated using the average score given by the 55 participants. Many strong correlations can be seen, and those that are statistically significant are marked with asterisks. There are strong positive correlations between return on investment (ROI) and credit rating, risk and professionalism, and negative correlations with proximity (to the end recipient of the investments) and social impact. Interestingly, social impact and proximity have strong negative correlations with risk, implying that on average, where the participants see risk as an important decision factor, they do not rate social impact as important, and vice versa.
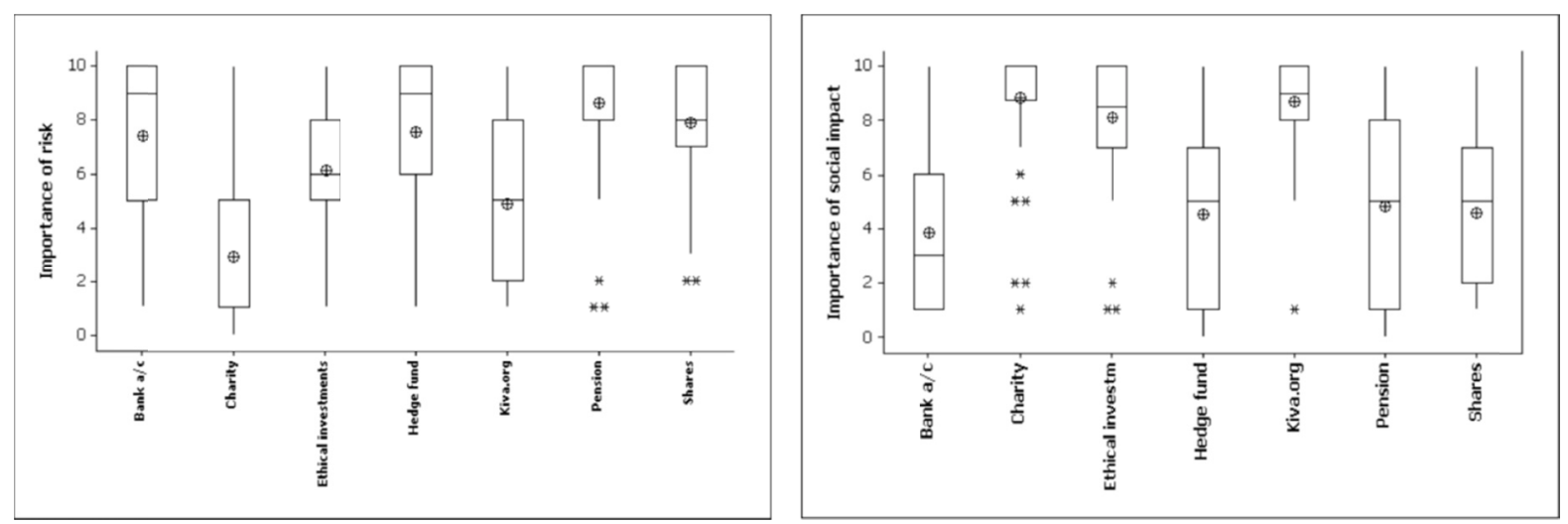

Figure 4. The left box-plot shows the importance of risk in making an investment decision

Note: $(0=$ unimportant, $10=$ important $)$. The right box-plot shows the importance of social impact in making an investment decision $(0=$ unimportant; $10=$ important)

Factor analysis has also been applied to search for the existence of a smaller number of underlying variables which might account for the complex patterns exhibited by the nine qualitative factors. Table 2 shows that just two factors can explain almost $99 \%$ of the variation, suggesting that this two-factor solution is highly representative of the nine qualitative variables. A Varimax rotation has been applied to the data, which seeks to make the factors more responsive to a smaller subset of the variables. 
The strongest factor, explaining $53 \%$ of the variance across the 9 qualitative factors, is highly correlated with variables such as social impact and proximity to the end recipient of the investments, as well as feedback and control over how the investment is used. For the purpose of this study, we name this first factor the 'social' factor Factor two in contrast is highly correlated with return on investment, the credit rating of the institution, the risk of the investment and the professionalism of the institution. We call this the 'financial' factor.

Table 1. Correlation matrix showing the correlation coefficients between each of the qualitative factors

\begin{tabular}{ccccccccc}
\hline & ROI & Reputation & $\begin{array}{c}\text { Credit } \\
\text { Rating }\end{array}$ & Risk & $\begin{array}{c}\text { Proxim } \\
\text { ity }\end{array}$ & $\begin{array}{c}\text { Feed- } \\
\text { back }\end{array}$ & $\begin{array}{c}\text { Professio } \\
\text {-nal }\end{array}$ & $\begin{array}{c}\text { Social } \\
\text { Impact }\end{array}$ \\
\hline Reputation & -0.004 & & & & & & & \\
Credit Rating & $\mathbf{0 . 8 8 7}^{* *}$ & 0.217 & & & & & & \\
Risk & $\mathbf{0 . 9 1 5}^{* *}$ & -0.124 & $\mathbf{0 . 9 2}^{* *}$ & & & & & \\
Proximity & $\mathbf{- 0 . 7 9 6}^{*}$ & 0.39 & -0.63 & $\mathbf{- 0 . 8 0 4}^{*}$ & & & & \\
Feedback & -0.529 & 0.416 & -0.587 & -0.719 & $\mathbf{0 . 8 3 6}^{*}$ & & & \\
Professional & $\mathbf{0 . 8 3 9}^{*}$ & 0.302 & $\mathbf{0 . 9 9 1}^{* * *}$ & $\mathbf{0 . 8 6 8}^{*}$ & -0.561 & -0.555 & & \\
Social Impact & $\mathbf{- 0 . 7 8 6}^{*}$ & 0.381 & -0.756 & $\mathbf{- 0 . 8 7 3}^{*}$ & $\mathbf{0 . 9 2 3}^{* * *}$ & $\mathbf{0 . 9 2 7}^{* * *}$ & -0.711 & \\
Control & -0.629 & 0.554 & -0.476 & -0.623 & $\mathbf{0 . 8 9 8}^{* *}$ & $\mathbf{0 . 8 4}^{*}$ & -0.427 & $\mathbf{0 . 9 0 5}^{* *}$ \\
\hline
\end{tabular}

${ }^{*} \mathrm{p}<0.05,{ }^{* *} \mathrm{p}<0.01,{ }^{* * *} \mathrm{p}<0.001$. Strong correlations are highlighted. Level of significance is indicated with asterisks.

Table 2. Factor analysis of averaged data across all nine qualitative factors

\begin{tabular}{cccc}
\hline \multicolumn{4}{c}{ Rotated Factor Loadings and Communalities } \\
Varimax Rotation & Communality \\
Variable & Factor1 & $\mathbf{0 . 9 6 4}$ & 0.976 \\
ROI & 0.214 & 0.683 & 0.993 \\
Reputation & $\mathbf{0 . 7 2 5}$ & $\mathbf{0 . 8 2 8}$ & 0.995 \\
Credit Rating & 0.556 & $\mathbf{0 . 9 4}$ & 0.99 \\
Risk & 0.326 & 0.291 & 0.985 \\
Proximity & $\mathbf{0 . 9 4 9}$ & 0.414 & 0.976 \\
Feedback & $\mathbf{0 . 8 9 7}$ & $\mathbf{0 . 7 4 3}$ & 0.992 \\
Professional & 0.663 & 0.245 & 0.994 \\
Social Impact & $\mathbf{0 . 9 6 7}$ & 0.551 & 0.996 \\
Control & $\mathbf{0 . 8 3 2}$ & 4.1369 & 8.8958 \\
Variance & 4.7589 & 0.46 & 0.988 \\
\% Var & 0.529 &
\end{tabular}

A value of 1 would indicate a perfect correlation of the values in the factor 1 and factor 2 columns, with each variable in the left-hand column (so they are correlations against the factors, rather than just factor scores). Strongest correlations are highlighted.

Plotting the position of the 7 different investment options in factor space using these variables as axes (Figure 5), shows that there are marked differences between the factors affecting decisions to invest in each option. It can be seen that Charity and Kiva.org, in the bottom right quadrant, score very highly on the social factor scale but low on the financial factor scale, while bank account, hedge fund, shares, and pension are high on the financial factor scale but low regarding social factors and thus in the top left quadrant. Thus the analysis is consistent with the idea that public investment decisions are not made purely in one dimension, based on a rational quantitative risk-return calculation, but include a second, negatively-correlated, dimension that incorporates more qualitative, social aspects of the investment. 


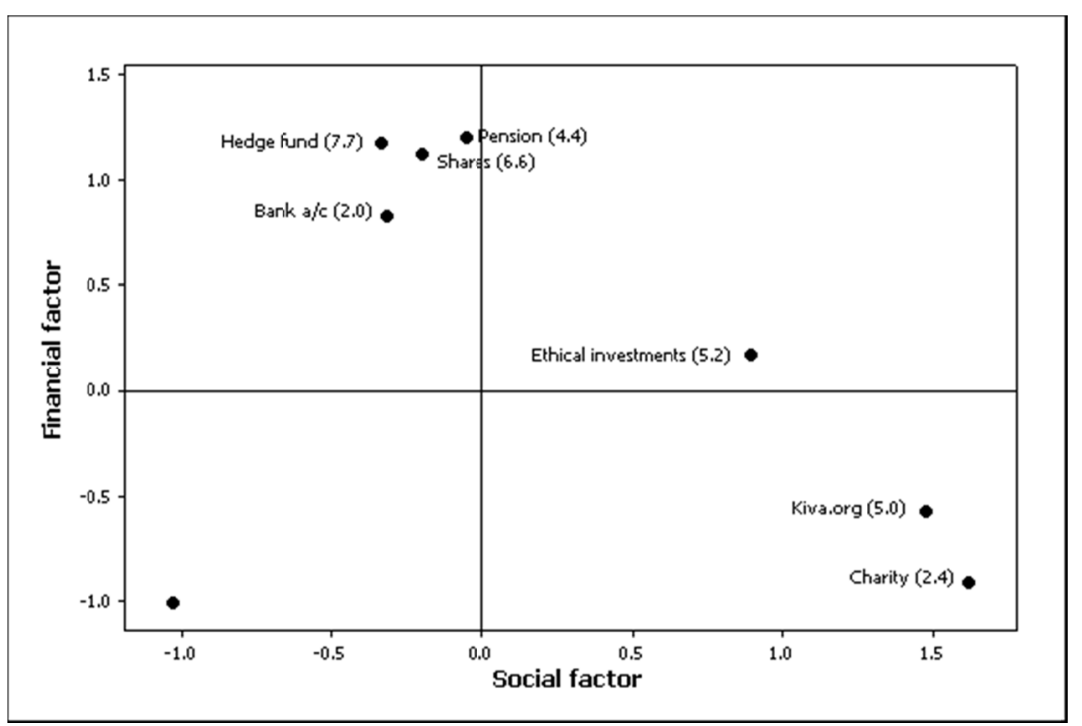

Figure 5. Two-factor diagram showing the positioning of each of the investment options against the two identified factors. The overall risk perception rating of each investment option is shown in brackets

Figure 5 also shows the average overall perceived risk rating of each option (in brackets next to each label). However, there is no discernable relationship between the perception of the overall risk of each investment type, and its position in this factor space. Were such a relationship to exist we would expect there to be a separation between the high risk investments and the low risk investments, with higher social impact causing a lower level of perceived risk. This would be consistent with the findings of Schutz and Wiedemann (2008), for example, who found that the risk perception of nanotechnology among the public decreases with the amount of societal benefit it is perceived to have, and with earlier work by Finucane et al. (2000) on the relationship between the risks and benefits of various technologies, and with theoretical studies by Vlaev et al. (2010) on domain effects and financial risk attitudes.

What might account for this departure? To answer this, it is first necessary to understand where the results differ from expectations. Charity, for example, is positioned as both very low risk and high on the social factor scale, in line with expectations. However charity is somewhat of an anomaly in this study because, unlike any of the other investment options, it offers zero chance of recouping one's initial investment. For this reason it is more prone to inconsistencies in its scoring, with this perplexity evident in the comments of some of the participants: "I wasn't sure how to rate charity in terms of risk - I thought the whole point was that you don't get your investment back!”

Bank accounts, on the other hand, scored very low on the social scale and high on the financial scale, but had the lowest risk rating of all the options, at just 2 out of 10 on average. Yet it is easy to understand why this would be the case - bank accounts are extremely safe investments in general and the risk perception clearly reflects that. They also have little social impact, apart from in the broadest sense of providing the public with a safe place to keep their money, and providing banks with funds upon which to leverage their lending activities. Therefore banks are represented more or less in their expected location on the factor space. In fact, the conclusion that this evidence seems to point to is that overall risk perception is not as important in influencing investment decisions as might have been expected.

\section{Discussion}

\subsection{Contrasting Ideologies}

A clear implication of these results is that perceived social impact, a feeling of proximity to the end beneficiary, feedback, and control over an investment are important to microfinance investors and can override the importance of risk levels in decision making. This is demonstrated by Kiva.org with its medium risk perception rating and which offers zero return on investment, but which is still a popular investment because of its high rating on social factors. In the absence of social factors, financial factors become understandably more important and judgements become based upon return on investment, credit rating and risk, regardless of whether the 
investment in question is perceived to be high or low risk.

These 'domain effects' are consistent with the view of Rhyne (1998), who believes that the two main schools of thought in microfinance, that of social impact and that of sustainability, are mutually exclusive, explaining that 'the sustainability camp views the private sector as the future home of microfinance, while those in the poverty camp seem wary of allowing that future to be dominated by commercial, for-profit operators.' The factor analysis indeed implies that this dichotomy is recognised within the wider public, including potential microfinance lenders.

\subsection{The Danger of Transferred Protocols}

What does this reveal about risk management in financial institutions? It may well be true that traditional financial institutions, such as banks, hedge funds, and pension funds are correct to place great importance in formal risk management, using tools such as credit ratings, and balancing risk with return on the investment, because this is how the public judge this type of investment. But for microfinance institutions or ethical investment firms who offer a social impact with their investments, these financial factors are apparently less important to their investors, and instead social factors take precedence. Therefore these institutions need to take this into account when designing their risk management policies, and indeed their general policies too.

Unfortunately, however, it is relatively rare that reports on the microfinance sector adequately acknowledge the contextual issues including consideration of mission and reputation, which are indicated here as important. Instead, there is a tendency to presume that what is good for the finance sector in general is also good for microfinance, a phenomenon which can be observed in the approach taken to risk assessment and management.

For example, one illuminating paper by consultants Oliver Wyman, on the future of risk management in microfinance draws comparisons between the microfinance industry and the US mortgage market, the latter a well-established market with sophisticated participants and risk management systems, and attempts to understand how the market collapse of 2007 can be avoided in the microfinance industry (Tantia, 2008). The author predicts that the microfinance industry could evolve to mirror the US mortgage market in many ways as the sophistication of the market increases, and the report goes on to advocate the use of 'best practice' risk management techniques, particularly in the areas of credit, market, and operational risk. This, however, begs the question of how one should define 'best practice' in the context of MFIs.

While it is clear that, faced with an increasing awareness of risks, old and new, the microfinance industry is placing more emphasis on risk management than ever before, the drivers to the implementation of subsequent risk policies are almost universally external forces, originating from the demands of the commercial investment funds and regulators that wish to impart a level of order on the industry that will result in greater stability and returns for them in the long-term. The danger is that, with a lack of internally driven risk management devices, the social mission of microfinance may not be reflected in the bulk of its decision-making procedures. That this could happen may be gleaned from scrutiny of the risk management protocols being proffered to MFIs, which seldom mention the social function of the sector.

As another example, a second report on risks to be managed by microfinance institutions lists counterpart risk, asset and liability balance, foreign currency exposure, and cash-flow risk as the four primary risks of concern (Bruett, 2004), all of which are financially-focused risks. Likewise, a leading framework for risk management in MFIs by a large German development organisation laments that: 'The social mission of MFIs attracts many high profile bankers and business people to serve on their boards. Unfortunately, these directors are often reluctant to apply the same commercial tools that led to their success (in banking) when dealing with MFIs.' In neither report is there clear acknowledgement of how suitable these tools might or might not be. The framework itself focuses primarily on financial and operational risks, only mentioning mission goals under the heading 'Additional Challenges for MFIs' (GTZ, 2000).

Likewise, some of the most comprehensive toolkits on offer barely mention risks to social function at all. MicroSave, an experienced and well-respected microfinance capacity-building organisation, brought out their Risk Management Toolkit in 2005. This highly detailed document on developing risk management policies for MFIs goes no deeper than an occasional sentence on mission goals, in fact using the word mission only four times during the 137 page document (Microsave, 2005). The CGAP MFI Appraisal Guide also recommends items that investors should look for when assessing MFIs. The section on risk management asks about the MFI's financial and operational risk management, but makes no mention of mission or reputational risk (Isern, Abrams and Brown, 2008).

A more modern approach to risk management is taken by an organisation called OSS360, whose risk 
management computer-based application aims 'to develop a $360^{\circ}$ risk management methodology for MFIs, including all kinds of risks (operational, financial, economic, strategic, et cetera)' and has the involvement of over 25 MFIs from around the world. Despite this involvement, its current iteration deals only with the more quantitative side of risk, such as portfolio and financing risk (Open Scenario Solution, 2011).

\subsection{Steering a True Course}

What should MFIs do? It is clear that within any complex system, such as that faced by an MFI, there are a large number of decisions to be made each day which, due inter alia to finite resources, are likely to have opportunity costs elsewhere. The philosopher David Seedhouse (2004) has proposed that in order to have an effective risk management policy, it is important to first decide on a philosophy or agreed purpose that underpins all decisions, and that this should be clearly stated and communicated. Without this, organisations are leaving themselves vulnerable to mission drift, as there will be no means of ensuring consistency in decisions and resource allocation.

This situation, it would appear, has been recognised in the new international standard on risk management, ISO 31000, which states that 'Management should align risk management objectives with the objectives and strategies of the organisation' (ISO, 2009). Also endorsing the importance of a properly designed risk philosophy, is the International Risk Governance Council (IRGC, 2008), an independent organisation whose purpose is to 'improve the understanding and management of emerging systemic risks that may have significant impacts on human health and safety, the environment, the economy and society at large.' The IRGC risk governance framework provides a logical analytic framework to aid comprehensive risk assessment and management strategies. One of the unique attributes of the model is that it takes into account the impact of societal context and the categorisation of different levels of risk-related knowledge, as well as promoting the value of a clearly defined purpose in forming the basis of any risk policy.

While all of this may seem obvious, it is often overlooked. With a huge number of risks to manage, references to the overall mission of the MFI often comprise just one small part of a gargantuan policy document, and seemingly comprise just one additional risk to manage but with no reference to its interconnectedness with the other parts of the policy. In fact, the MFI's mission, and overall philosophy, should be embedded in all decisions made by the organisation. It is salutary to note that many MFIs who state their primary mission as being poverty reduction make decisions that have the opposite effect, examples of which include collateral requirements, efficiency drives and cost reduction, and lending in hard currencies. The events in the Indian state of Andhra Pradesh in 2010, in which MFIs were subject to scandal and government criticism due to their over-zealous credit policies, could themselves be said to be the result of a lack of consistency of internal policies and insufficient awareness of social risks, as profit motives and credit policies clashed with the social goals of microfinance (CGAP, 2010).

\subsection{Inevitability of Trade-Offs}

It is inevitable that risk managers in MFIs will face complex issues arising from the varying beliefs of stakeholder groups. Consequently they should be prepared for, and understand, the nature of the conflicts. Although, in some circles, there exists the idea that risk management is something to look to in times of conflict and uncertainty as a way to organise debates and arrive at rational decisions, the reality is that society has multiple goals and difficult trade-offs have inevitably to be made, often on grounds which are not strictly 'rational' (Graham and Wiener, 1995). This is likely to be particularly so in the microfinance industry with its dual and often opposing motives.

It may also be worth bearing in mind that in the wider risk world it has been noted that the incorporation of values into risk management policies, the need for which is argued here, is in itself tantamount to adopting a certain philosophy, and that there are many who oppose this. Those who have argued in favour of this tend to be ones who believe risks to be social constructions, otherwise known as 'constructivists,' such as Hillgartner (1992), or Luhmann (1995). However, there is a second camp, the 'realists,' who fervently believe that risks can be reduced to accurate technical representations of the hazards that exist, and that will affect people in the same manner regardless of their perceptions (Catton, 1980; Dickens, 1992).

Constructivists, such as Freudenberg and Pastor (1992), contend that cognitive perceptions must be integrated into the regulatory decision process to enable effective decision-making, as assessments are not valid outside of the logical framework of the group conducting them. In other words, one must take into account those affected by the risk and how much they are willing to tolerate, before making judgements on what to do about it. An example from the microfinance industry is that, while realists would argue that requesting collateral from all clients can statistically reduce the risk that they will default and the MFI lose its money, constructivists would 
point out that MFIs with a social mission are likely to have a higher tolerance of this type of risk in favour of reaching poorer clientele.

\section{Conclusions}

Divergence of opinion over the nature and conduct of the business of MFIs is well known. Zeller and Meyer (2002) describe it in terms of a 'triangle of microfinance' - a constant balancing act that microfinance institutions must walk between outreach (reaching large numbers of poor clients), financial sustainability (generating sufficient revenues to cover all costs), and impact (showing a positive effect on clients' quality of life). Rhyne (1998) describes the split as a dichotomy between those who believe microfinance should focus on poverty reduction, and those who believe it should focus primarily on being sustainable. These are seen as mutually exclusive, because in order to reach the very poor, one must travel to more and more remote areas to deliver smaller and smaller loan sizes, thus increasing operating costs and reducing efficiency.

There are, evidently, two main drivers behind the framing of the microfinance industry, the first being differing motivations and values of the key industry stakeholders, including governments and increasingly the lending public. These stakeholders are split between those with a purely social motive, and those with a dual profit and social motive. The second dimension is the context of the industry itself, started with the primary purpose of alleviating poverty, but which, almost coincidentally, shares many practical similarities to the global financial services sector, hence attracting resources, its practices and values.

Overall, this indicates that MFIs would be well advised to put more resources into measuring and reporting their social impact, and providing investors with transparency on the use of their funds and the motivations behind the decisions which they make, things that are often not included in current risk audits. Furthermore, other social factors which are important to lenders rarely receive a mention in the risk management protocols which have been developed. MFIs need to respond firmly by integrating consideration of their mission into all their management protocols.

\section{References}

ADA (Appui au DéveloppementAutonome). (2012, September). Les Midis de la Microfinance-La Microfinance: outil de luttecontre la pauvreté. Retrieved from http://www.microfinance.lu/fileadmin/media/Documents/Midis_de_la_microfinance/Dossiers_th\%C3\%A9 matiques $/ 2 \% \mathrm{C} 3 \% \mathrm{~A} 8 \mathrm{me}$-Midi_Outil_de_lutte_contre_le_pauvret\%C3\%A9.pdf

Al-Azzam, M., Mimouni, K., \& Ali, M. A. (2012). The impact of socioeconomic factors and financial access on microfinance institutions. International Journal of Economics and Finance, 4(4), 61-71. http://dx.doi.org/10.5539/ijef.v4n4p61

Al-Mamun, A., Adaikalam, J., \& Wahab, S. A. (2012). Investigating the effect of AmanahIkhtiar Malaysia's microcredit program on their clients quality of life in rural Malaysia. International Journal of Economics and Finance, 4(1), 192-203.

Ayayi, G. A. (2012). Credit risk assessment in the microfinance industry. Economics of Transition, 20(1), 37-72. http://dx.doi.org/10.1111/j.1468-0351.2011.00429.x

Bhattamishra, R., \& Barrett, C. (2010). Community-based risk management arrangements: A review. World Development, 38(7), 923-932. http://dx.doi.org/10.1016/j.worlddev.2009.12.017

Bruett, T. (2004). Four risks that must be managed by microfinance institutions. Retrieved from http://www.microfinancegateway.org/gm/document-1.9.28383/21962_Microfinance_Experience_pdf

Catton, W. R. (1980). Overshoot: The ecological basis of revolutionary change. Urbana, Illinois: University of Illinois Press.

CGAP (Consultative Group to Assist the Poor). (2008). Who is funding microfinance? Results of the first global survey of funders' microfinance portfolio. Retrieved from http://www.cgap.org/gm/document-1.9.7448/2008\%20Funder\%20Survey-resource\%20presentation\%20fina l.pdf

CGAP (Consultative Group to Assist the Poor). (2010). Andhra pradesh: Global implications of the crisis in Indian microfinance. Retrieved from http://www.cgap.org/gm/document-1.9.48945/FN67.pdf

Dickens, P. (1992). Society and nature: Towards a green social theory. Philidelphia: Temple University Press.

Dieckmann, R. (2007). Microfinance: An emerging investment opportunity. Deutsche Bank. Retrieved from http://www.dbresearch.com/PROD/DBR_INTERNET_EN-PROD/PROD0000000000219174.pdf 
Fernando, N. (2008). Managing microfinance risks: Some observations and suggestions. Asian Journal of Agriculture and Development, 4(2). Retrieved from http://www.microfinancegateway.org/gm/document-1.9.31063/50997_file_Managing_Microfinance_Risks. pdf

Finucane, M. L., Alhakami, A., Slovic, P., \& Johnson, S. M. (2000). The affect heuristic in judgments of risks and benefits. Journal of Behavioral Decision Making, 13, 1-17. http://dx.doi.org/10.1002/(SICI)1099-0771(200001/03)13:1<1::AID-BDM333>3.0.CO;2-S

Freudenberg, W. R., \& Pastor, S. K. (1992). Public responses to technological risk. Sociological Quarterly, 33(3), 389-412. http://dx.doi.org/10.1111/j.1533-8525.1992.tb00381.x

Graham, J. D., \& Wiener, J. B. (1995). Risk versus risk. Cambridge, Mass: Harvard University Press.

GTZ (Deutsche Gesellschaftfür Technische Zusammenarbeit). (2000). A risk management framework for microfinance institutions. Retrieved from http://www.gtz.de/en/dokumente/en_risk_management_framework_for_MFI.pdf

Hartarska, V., \& Nadolnyak, D. (2007). Do regulated microfinance institutions achieve better sustainability and

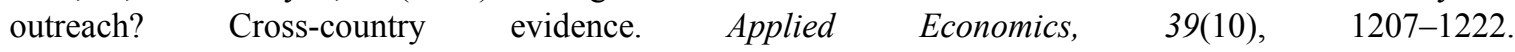
http://dx.doi.org/10.1080/00036840500461840

Hillgartner, S. (1992). The social construction of risk objects. In Short, J. F., \& Clarke, L. (Eds.), Organisations, Uncertainty, and Risk (pp. 39-53). Colorado: Westview.

IRGC (International Risk Governance Council). (2008). An introduction to the IRGC Risk Governance Framework. Geneva: IRGC. Retrieved from http://www.irgc.org/IMG/pdf/An_introduction_to_the_IRGC_Risk_Governance_Framework.pdf

Isern, J., Abrams, J., \& Brown, M. (2008). Appraisal guide for microfinance institutions. Retrieved from http://cgap.org/gm/document-1.9.4394/MFIAppraisalTechnicalGuide.pdf

ISO (International Organization for Standardization). (2009). ISO 31000-Risk management-Principles and guidelines. Geneva: ISO.

Luhmann, N. (1995). Risk: A sociological theory. Berlin: de Gruyter.

Microsave. (2005). Institutional and product development risk management toolkit. Retrieved from $\mathrm{http}: / / \mathrm{www}$.microsave.org/toolkit/institutional-and-product-development-risk-management-toolkit

Open Scenario Simulation. (2010). OSS360: An overall risk management method of all risks for MFIs. Retrieved from http://www.oss360.org/en/

Rahman, M. W., \& Luo, J. (2011). The development perspective of finance and microfinance sector in China: How far is microfinance regulations? International Journal of Economics and Finance, 3(1), 160-170.

Rhyne, E. (1998). The yin and yang of microfinance: Reaching the poor and sustainability. MicroBanking Bulletin, 7, 6-8. Retrieved from http://www.jointokyo.org/mfdl/readings/Rhyne-yingyang.pdf

Schutz, H., \& Wiedermann, P. (2008). Framing effects on risk perception of nanotechnology. Public Understanding of Science, 17(3), 369-379. http://dx.doi.org/10.1177/0963662506071282

Seedhouse, D. (2004). Health promotion-philosophy, prejudice and practice.

Slovic, P. (2010). The feeling of risk: New perspectives on risk perception. London and Washington: Earthscan.

Tantia, P. (2008). The future of risk management in microfinance: Perspectives from practitioners in the US financial markets. Oliver Wyman Consulting \& the Center for Emerging Market Enterprises. Retrieved from http://fletcher.tufts.edu/CEME/publications/ /media/Fletcher/Microsites/CEME/newpdfs/OW_MFPaper_FI NAL_06-30-08.ashx

Vlaev, I., Kusev, P., Stewart, N., Aldrovandi, S., \& Chater, N. (2010). Domain effects and financial risk attitudes. Risk Analysis, 30(9), 1374-1386. http://dx.doi.org/10.1111/j.1539-6924.2010.01433.x

Yunus, M. (1999). Banker to the Poor: Micro-lending and the battle against world poverty. New York: Public Affairs.

Zeller, M., \& Meyer, R. (2002). The triangle of microfinance: Financial sustainability, outreach, and impact. Retrieved from http://ageconsearch.umn.edu/bitstream/16592/1/fp020040.pdf 


\section{Notes}

Note 1. P2P refers to the recent development in microfinance whereby socially-minded internet users can lend small sums of money via the internet to microfinance institutions such as Kiva.org, MicroPlace.com and MicroWorld.org and their clients.

Note 2. Kiva.org was used to represent microfinance investments as it is the best known of all peer-to-peer platforms.

Note 3. How important is the risk to you in making the decision, not how risky is the option overall.

Note 4. How close you feel to the person that eventually uses the investment, e.g. if you buy shares, the end beneficiaries could be the employees and customers of the company you buy shares in.

\section{Copyrights}

Copyright for this article is retained by the author(s), with first publication rights granted to the journal.

This is an open-access article distributed under the terms and conditions of the Creative Commons Attribution license (http://creativecommons.org/licenses/by/3.0/). 